\title{
Acontecimientos y figuras de la Revolución rusa a través del prisma de Mariátegui*
}

\begin{abstract}
RESUMEN
El artículo revisa la obra periodística y las conferencias de José Carlos Mariátegui sobre la Revolución rusa. La selección de artículos que se analizan versa, principalmente, sobre la política del Gobierno soviético y sus acciones diplomáticas, la obra cultural de la Revolución y los debates en el Partido Comunista de la Unión Soviética durante los años veinte. Además, refiere las valoraciones de Mariátegui acerca de algunos de los principales dirigentes políticos de la República soviética; en particular, se analiza sus escritos sobre León Trotsky.
\end{abstract}

Palabras Clave: Revolución rusa; Partido Comunista de la Unión Soviética; URSS; Mariátegui; Trotsky

\section{Events and figures of the Russian Revolution through the prism of Mariátegui}

\begin{abstract}
The article reviews the journalistic work and the conferences of José Carlos Mariátegui about the Russian Revolution. The selection of articles analyzed is mainly about the policy of the Soviet Government and its diplomatic actions, the cultural work of the Revolution and the debates in the Communist Party of the Soviet Union during the 1920s. In addition, it refers to Mariátegui's evaluations of some of the main political leaders of the Soviet Republic; in particular, his writings on Leon Trotsky are analyzed.
\end{abstract}

KeYwords: Russian Revolution; Communist Party of the Soviet Union; USSR; Mariátegui; Trotsky

Artículo basado en la ponencia sustentada en el Simposio «Mariátegui volvió para quedarse», celebrado en la Casa Museo José Carlos Mariátegui del 24 al 25 de mayo de 2013. Agradezco a mi amigo y colega Ricardo Portocarrero, quien por entonces dirigía dicha institución, por invitarme a participar en aquel simposio que conmemoró el noventa aniversario del retorno de Mariátegui al Perú. Expreso también mi gratitud al historiador y amigo Luis Bustamante Otero por sus comentarios y recomendaciones a la versión preliminar de este artículo. 


\section{Introducción}

L a Revolución rusa y el orden socialista que se empezara a gestar en el otrora Imperio de los zares, fueron tópicos a los que José Carlos Mariátegui consagró artículos periodísticos y conferencias en el curso de la década de 1920. El rol del Partido Bolchevique en la marejada revolucionaria, la instauración del régimen de los sóviets y el experimento social que se implantaba en Rusia -el primero de su naturaleza en la historia mundial- abrió cauce, desde sus inicios, a una frondosa literatura, tanto la escrita por sus participantes y testigos directos cuanto por visitantes extranjeros que se hallaban en Petrogrado durante los «diez días que estremecieron al mundo", frase con que el periodista norteamericano John Reed tituló su difundida crónica acerca de los sucesos del año 17.

Por aquellas fechas, la prensa mundial publicó extensos informes y reportajes a la revolución social acaecida en la tierra de Pushkin y Tolstói. La línea editorial de los principales órganos periodísticos occidentales fue meridianamente hostil hacia la República soviética. Otros medios de prensa informaron de manera más o menos objetiva, consiguiendo satisfacer la curiosidad y avidez de un sector de la opinión pública, tal como lo expresara el Amauta (Mariátegui 1986, p. 55).

En el Perú, las informaciones tocantes a la Revolución rusa hallaron en la prensa su principal medio de difusión, puesto que una reducida fracción de los libros que abordaban tal hecho arribaría a nuestro país con cierta dilación. Los cables telegráficos, que notificaban de su estallido y de la abdicación del último autócrata Románov, impresionaron al joven José Carlos Mariátegui, a la sazón redactor del diario El Tiempo. Cabe recordar que en esos días, desde las columnas de aquel diario, Mariátegui manifestó su ostensible inclinación por el socialismo, y ello provocó que Luis Miró Quesada, director de El Comercio, le endilgara el calificativo de "bolsheviqui» (Rouillon, 1975 , p. 202). En aquel tiempo, los bolcheviques eran juzgados por ciertos sectores de la política limeña como una «menguada horda de malhechores de la peor laya y de las más innoble catadura» (Mariátegui 1977, p. 45). Sin rebozo, Mariátegui, en el artículo "Bolsheviquis, aquí», publicado en El Tiempo el 9 abril de 1918, expresó que había «abrazado con ardimiento y fervor" tal calificativo (Mariátegui 1977 , p. 44). Ello acontecía varios años antes de que Mariátegui se afirmara como marxista.

Durante su estada en Europa, entre los años 1919 y $1923^{1}$, Mariátegui allegó textos sustanciales concernientes a la Rusia soviética y estudiaría con hondura su organización política, la esfera socioeconómica, las conquistas sociales y culturales de la Revolución y su repercusión mundial. Otra materia que embebió su atención concernía a la floración de escritores rusos y su obra, impregnada de ideales revolucionarios. En sus exploraciones sobre la realidad soviética, Mariátegui leyó los escritos teóricos y políticos de los representantes de la joven república; y dedicó originales y cuidadosos análisis referidos a los cambios radicales y las relaciones diplomáticas y económicas de los sóviets con los Estados de la órbita capitalista. Entre 1917 y 1930 escribió alrededor de cuarenta artículos sobre Rusia.

\section{El periplo europeo}

Es sabido que las experiencias vitales y las lecturas que Mariátegui acometió en Europa, ampliaron sus horizontes y le dotaron de una cultura ecuménica. Asimismo, fue en el Viejo Continente donde se terminaron de forjar sus convicciones socialistas. Mariátegui arribó a Italia en las postrimerías de 1919, año crucial para los destinos de Europa en virtud de la firma de los tratados de paz entre los Aliados y las Potencias Centrales. En esta coyuntura, observó con atención la severa crisis de posguerra que atravesaba el continente. Mariátegui hubo de permanecer en Europa por espacio de tres años y siete meses, residiendo en Italia durante más dos años y medio y en Francia y Alemania en el intervalo de algunos meses.

Además de presenciar los efectos del conflicto bélico en los países que visitó, accedió a la obra de intelectua-

1 Con el propósito de «intensificar la labor de propaganda peruana en la prensa extranjera", el Ministerio de Relaciones Exteriores designó a Mariátegui como agente en Italia para el desempeńo de esa comisión, asignándole un ingreso mensual de cuarenta y cinco libras esterlinas, tal como consta en la Resolución Suprema de carácter reservado, firmada por el canciller Melitón Porras, fechada en Lima el 18 de septiembre de 1919. Esta disposición del gobierno de Leguía ha sido interpretada como una medida política para mantenerlo alejado del Perú. El documento se halla en Resoluciones y Decretos Supremos, correspondientes al año 1919, en el Archivo Central del Ministerio de Relaciones Exteriores del Perú. 


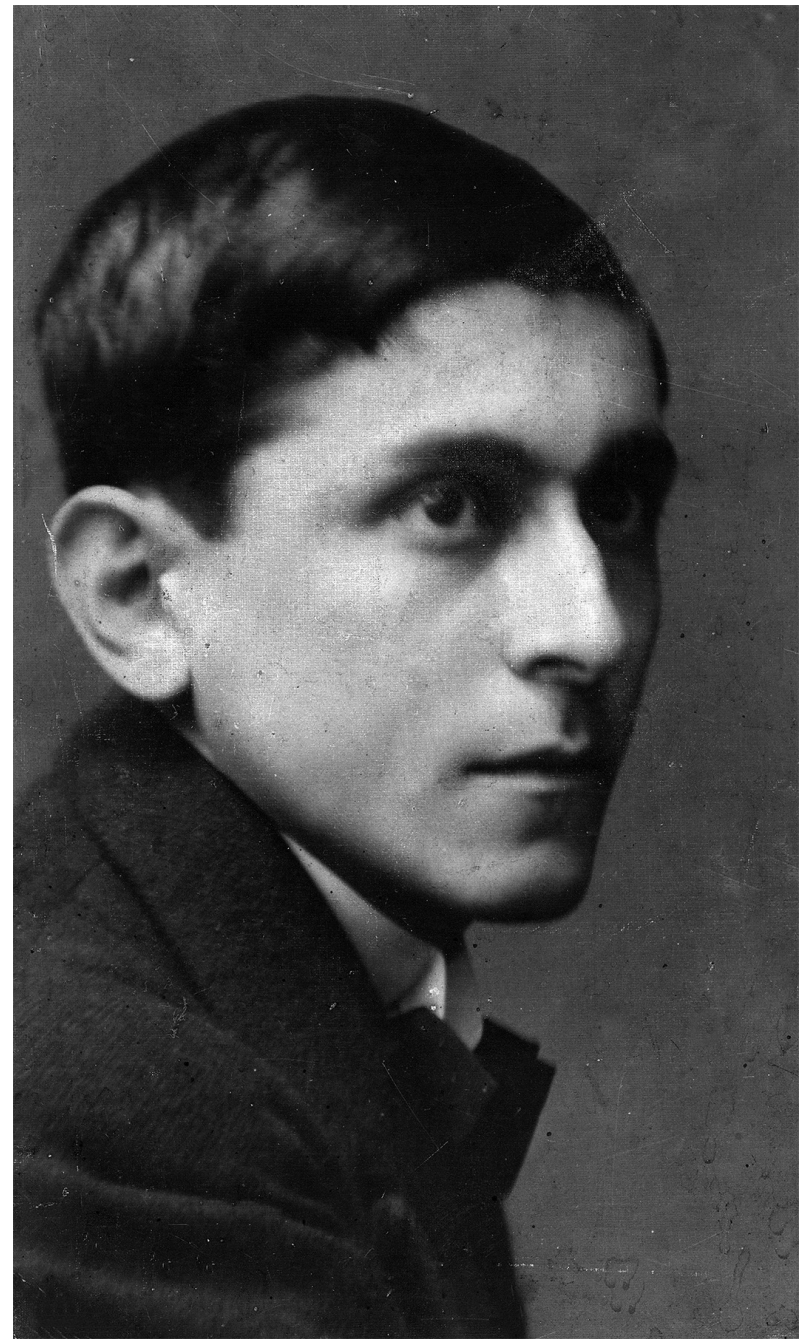

José Carlos Mariátegui

les e ideólogos del socialismo europeo. Tanto en la península itálica, como en Francia y Alemania, obtuvo un conocimiento directo de las obras del pensamiento político contemporáneo y de las vanguardias literarias. La nómina de autores y obras es vasta, pero habría que recordar que entre sus escritores franceses predilectos figuraban Georges Sorel, Romain Rolland y Henri Barbusse (Núñez 1994, pp. 39-41). Mariátegui leyó a estos en su idioma original (había aprendido las lenguas italiana, francesa y alemana), y conoció las obras de políticos rusos (Lenin, Trotsky, Zinóviev) por las traducciones, sobre todo las versiones francesas ${ }^{2}$.

2 En cuanto a la adquisición de libros, parte considerable de estos procedieron de París. Estuardo Núnez observó que, entre 1927 y 1929 , la mitad de la biblioteca de Mariátegui estaba constituida por libros en francés (Núñez, 1994, p. 38).
Cada uno de los autores leídos influyó en diferente grado en su evolución ideológica. Destaca de su formación intelectual la pluralidad de tendencias que asimiló. Ello pone de relieve un rasgo distintivo del pensamiento mariateguiano, cual fue su heterodoxia; su aprehensión de diversas corrientes de la civilización occidental le apartaron de cualquier visión dogmática y sectaria.

Amén de lo dicho, en Europa hubo de conocer a dos destacadas personalidades rusas: Gueorgui Chicherin, comisario de Asuntos Extranjeros, a quien conoció en Génova, y a Máximo Gorki en Alemania a fines de 1922. En aquella circunstancia, Gorki se hallaba internado en el Neue Sanatorium de Saarow Ost, localidad en las proximidades de Berlín. Mariátegui ha escrito que Gorki sólo hablaba ruso y que, para conseguir entrevistar al autor de La Madre, contó con la colaboración de la esposa del novelista, María Fiódorovna Andréieva, quien era políglota (Mariátegui 1925, p. 228).

De otro lado, debe recordarse que, en aquel tiempo, Mariátegui proyectaba la realización de un viaje a la Unión Soviética, país sobre el que se había informado ampliamente; empero, la escasez de recursos económicos y, sobre todo, su frágil salud no permitieron su consecución.

\section{Rusia y las relaciones internacionales}

Durante su estancia en Italia, Mariátegui escribió un primer artículo sobre la actualidad rusa, fechado en Roma el 12 de febrero de 1920 y publicado en El Tiempo de Lima el 9 de julio de 1920, bajo el título de «La Entente y los Soviets».

En el aludido texto periodístico refiere que, después de que el Gobierno francés se opusiera a suscribir acuerdos con la República soviética, en la Conferencia de París, de consuno con Gran Bretaña, el gobierno de Raymond Poincaré aprobó anudar relaciones comerciales con las cooperativas rusas, que eran dependientes del Estado. A partir del antedicho convenio, Mariátegui barruntaba el reconocimiento internacional del Estado soviético.

Indicó que eran varios y complejos los factores que habían conducido a un viraje en las relaciones con Rusia, y reconocía que definirlos entrañaba una dificultad por cuanto no se tenía a disposición 
los suficientes elementos de juicio. Ello no obstante, Mariátegui ensayó un análisis considerando una conjunción de factores, entre los que anotó el componente interno (la clase obrera en Inglaterra, Italia y Francia, a través de su representación parlamentaria, había demandado la paz con la República soviética), el factor militar (la victoria del Ejército Rojo sobre los ejércitos aprovisionados y financiados por los países de la Entente), el elemento económico (Rusia requería de la manufactura de los países de Europa Occidental y aquellos de las materias primas de Rusia, principalmente de cereales) y el ingrediente político (en tanto el gobierno de David Lloyd George auguraba que, a través del comercio, se podría extenuar al régimen soviético, los bolcheviques, por su parte, confiaban en que, merced a las exportaciones de cereales, conseguirían la tregua necesaria para consolidar su sistema). A partir de sus análisis, Mariátegui prefiguraba que, en la Conferencia de Londres convocada para julio de 1920, habría de producirse un acercamiento hacia Rusia.

Y concluía su artículo, declarando que:

La paz entre Inglaterra y Rusia no será la paz entre dos naciones. No será la paz entre dos imperialismos. No será una paz local. Será la paz entre el estado mayor del capitalismo y el estado mayor de la revolución social. Una paz, que en el fondo no será, naturalmente, sino un armisticio (Mariátegui 1991, p. 56).

Conforme se ha visto, Mariátegui inquirió sobre las relaciones internacionales del Estado soviético, interés que se expresó en la escritura de un puñado de artículos. En uno de ellos, titulado «La ruptura anglo-rusa», publicado en Variedades el 4 de junio de 1927, explica, a propósito de la interrupción de relaciones entre la URSS y Gran Bretańa que, a pesar de haber mantenido vínculos comerciales y relaciones diplomáticas entre ambos países, el estado de guerra activo o latente no había cesado.

Esta ruptura fue decidida por la política conservadora del gobierno de Stanley Baldwin, que advertía una amenaza en la propaganda comunista y la agitación revolucionaria en Asia y África. Anotaba Mariátegui que tal situación amenazaba las posesiones coloniales del Imperio Británico, cuyo rol hegemónico en la economía mundial había declinado ante los Estados Unidos, erigido en eje del desarrollo capitalista. Y, a propósito de las nuevas orientaciones de la política global, advirtió con gran clarividencia: «Rusia y Estados Unidos son hoy los dos polos de la historia del mundo» (Mariátegui 1989, p. 184).

Por causa de la declinación política y económica de Gran Bretańa, concluía que la ruptura de sus relaciones con Rusia sería «un acto de mucha menor trascendencia mundial» que en 1924, año en que restablecieron vínculos.

Es de resaltar en los escritos de Mariátegui sobre sucesos de la esfera internacional, el enfoque de varios factores concurrentes, en donde lo económico implicaba un componente gravitante entre otros de naturaleza política e ideológica. A tenor de esta perspectiva, es admisible sostener que en sus análisis no asoman rasgos de economicismo, visión asociada a ciertas expresiones del marxismo.

\section{Las conferencias en la Universidad Popular «González Prada»}

Poco después de su retorno al Perú, Mariátegui fue invitado a dictar conferencias en la Universidad Popular, institución que animaba la Federación de Estudiantes. Aquellas disertaciones fueron impartidas en el curso de 1923 hasta enero del año siguiente, y llevaron el título general de "Historia de la crisis mundial $»^{3}$. El público al que, preponderantemente, estaban dirigidas era la clase obrera de Lima.

La quinta conferencia de aquel ciclo abordó la Revolución rusa. Anunciaba Mariátegui (1986) que la disertación sería «demasiado elemental, demasiado rudimentaria» (p. 56). Hecha la salvedad, expone un panorama acerca de los sucesos revolucionarios en 1917 y el cariz político de los partidos actuantes y de su fuerza social.

De la sucinta relación que presentara, hemos de referir el juicio que mereció a Mariátegui el Gobierno Provisional surgido de la Revolución de Febrero, bajo la presidencia de Aleksandr Kerenski. Anota de aquel gobierno, integrado por liberales y socialistas, un «conglomerado heterogéneo, anodino, incoloro»

3 El título escogido por Mariátegui se debía a que sus conferencias examinaban la crisis de la civilización capitalista y de sus instituciones. Según el ponente, de aquella crisis nacería la civilización proletaria, la civilización socialista. 


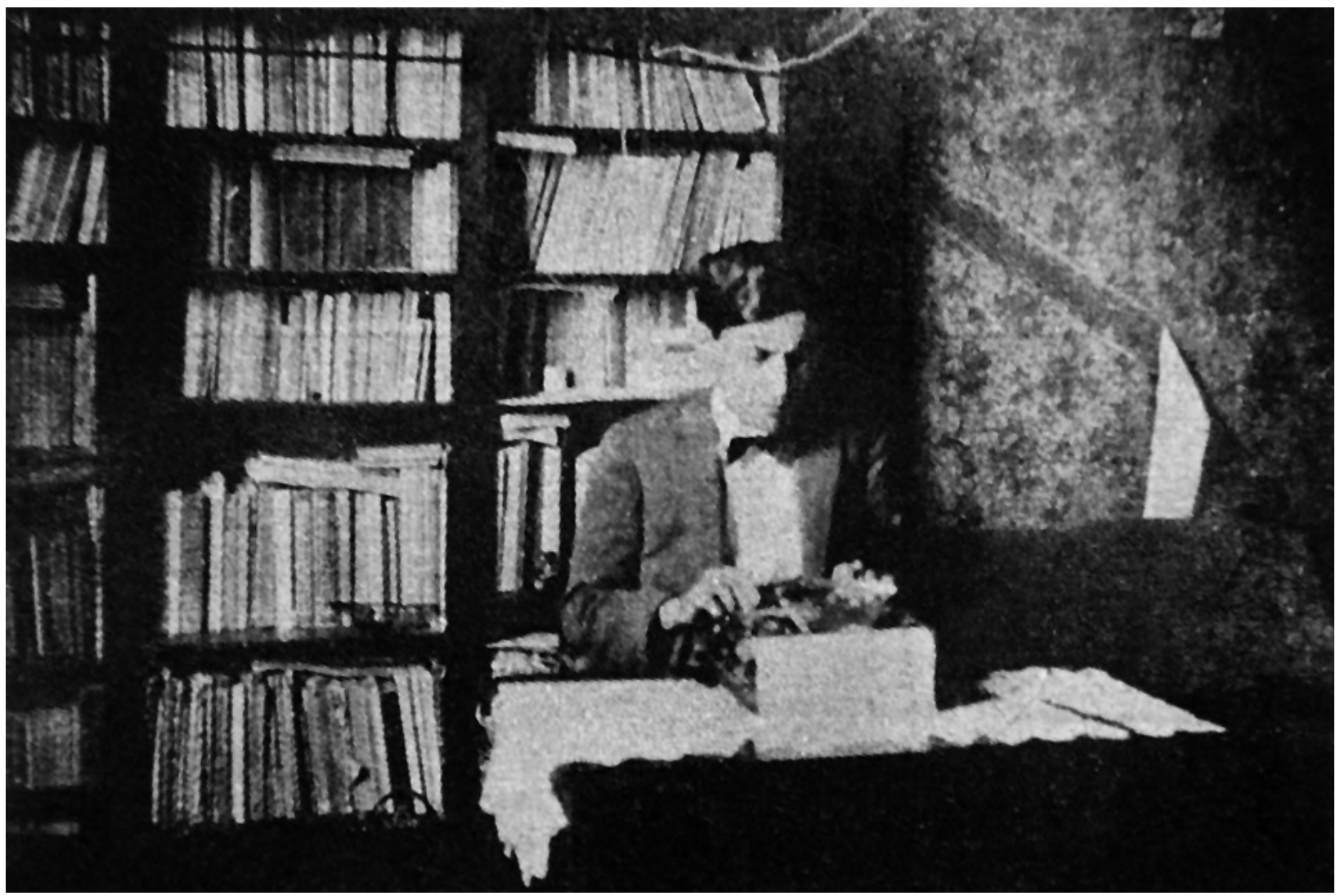

José Carlos Mariátegui en su escritorio de la casa Washington Izquierda 544, Lima.

(Mariátegui 1986, p. 57). Explica su debilidad por tratarse de un gobierno de coalición en una coyuntura revolucionaria, conclusión a la que arribarían otros analistas de la Revolución rusa ${ }^{4}$. A este respecto, precisa desde un enfoque marxista-leninista que:

Un gobierno revolucionario tiene que ser, por fuerza, un gobierno de facción, un gobierno de partido, debe representar únicamente a los núcleos revolucionarios de la opinión pública; no debe comprender a los grupos intermedios, no debe comprender a los núcleos virtualmente, tácitamente conservadores» (Mariátegui, 1986, p. 57).

Y prosigue sosteniendo que el gobierno de Kerenski adolecía de un «defecto orgánico», que era el de no encarnar los ideales del proletariado ni tampoco los de la burguesía. Por contraste, los bolcheviques orienta-

4 A modo de ejemplo, un testigo de los acontecimientos de 1917, Nikolái Sujánov, escribe en su crónica: «Ante todo, la nueva coalición creada por Kerenski, no podía sobrevivir. Su suerte estaba ligada a toda la coyuntura y al hecho de que el poder efectivo estaba ya prácticamente en manos de los bolcheviques.» (Sukhanof 1970, p. 343) ron su propaganda con sagacidad en un sentido popular: demandaron la paz inmediata con las Potencias Centrales y el reparto de las tierras. Ello explicaba que los bolcheviques obtuvieran la mayoría en los sóviets de Petrogrado y de otros centros industriales.

Destaca Mariátegui que la frustrada ofensiva del 18 de junio de 1917, lanzada por el Gobierno Provisional contra los ejércitos austroalemanes, seńalaría un punto de inflexión. A partir de entonces, la impopularidad del régimen se acentuó y extendió. Tras el intento de golpe contrarrevolucionario del general Kornílov - abortado por la resistencia de los obreros de Petrogrado-, el Sóviet obtuvo la adhesión de la guarnición de la capital y este hecho preludiaría el triunfo de las fuerzas revolucionarias sobre el Gobierno Provisional.

El 19 de octubre de 1923, en la decimocuarta conferencia en la Universidad Popular, Mariátegui disertó nuevamente sobre la Rusia soviética, esta vez sobre sus instituciones de gobierno. Esta era una materia de singular interés, considerando su desconocimiento en el Perú. No se conserva el texto de la conferencia, 
pero sí el esquema y el guión, además de una crónica periodística sobre el evento. En esta disertación, Mariátegui informó, también, acerca de las conquistas de la Revolución en el sistema laboral, en la educación, en la asistencia de la infancia, y abordó la situación de la mujer en el Estado soviético; además, explicó los resultados de la Nueva Política Económica, instaurada por el Gobierno de Lenin en 1921.

\section{Figuras del régimen soviético}

En su perspectiva de la revolución social, a contracorriente de otras interpretaciones marxistas, Mariátegui no desdeñó el papel del individuo en la historia. En las secciones "La escena contemporánea» $\mathrm{y}$ "Figuras y aspectos de la vida mundial» de la revista Variedades, trazó perfiles de representantes del Gobierno soviético, de los que apuntó sus orígenes sociales, aspectos de su fisonomía política y de su trayectoria al servicio de la Revolución.

En esa tesitura, escribió un artículo sobre Lenin, en el que pretende calibrar su personalidad revolucionaria, basándose en algunos de los retratos que de él expusieran sus coetáneos. En este subraya como elementos esenciales su rol de agitador y de líder político, el de «estratega y de conductor de muchedumbres y de pueblos» (Mariátegui 1923, p. 2585). Esencialmente, aprecia en el fundador del Partido Bolchevique a un realizador, antes que a un teórico o ideólogo, caracterización de suyo opinable.

También destinó páginas a la obra educativa de Anatoli Lunacharski, comisario de Instrucción Pública de los Sóviets, destacando sus realizaciones en este terreno —que Mariátegui juzgaba como la «obra más sólida» de la Revolución-. En efecto, Lunacharski había asumido el encargo de echar las bases de una cultura proletaria en Rusia. Ello se verificaba, por ejemplo, en la política sobre los museos públicos, cuyas obras de arte —que antaño pertenecían a colecciones privadas - contribuían a la educación artística del pueblo. Añadía, sin embargo, que su labor más fecunda se efectuaba en la escuela. Bajo los sóviets, el número de escuelas, convertidas en instituciones mixtas y laicas, era varias veces mayor que las sostenidas por el régimen zarista. Por lo expresado, Lunacharski aparecía "como uno de los más altos animadores y conductores de la revolución rusa. Quien más profunda y definitivamente está revolucionando a Rusia...» (Mariátegui 1925, p. 128).

Entre los revolucionarios rusos cuya obra atrajo la atención de Mariátegui se hallaba Grigori Zinóviev, del que reseñó su labor de agitación en la presidencia de la Tercera Internacional. A esta faceta, agregaba las de polemista, panfletario y tribuno; pero de Zinóviev destacaba, sobre todo, ser «un depositario de la doctrina de Lenin, un continuador de su obra» (Mariátegui 1925, p.141).

Menos recordado en la actualidad, pero no por ello una figura menor, es Gueorgui Chicherin, a quien Mariátegui valoraba como el representante más interesante y singular de la diplomacia contemporánea (Mariátegui 1988, p. 64). Gracias a su gestión en el Comisariato de Asuntos Extranjeros, Rusia fue readmitida en la comunidad internacional. Un logro de su conducción fue, verbigracia, el Tratado de Rapallo, acuerdo de amistad y cooperación suscrito con Alemania en 1922, que significó el primer reconocimiento de los Sóviets por un Estado capitalista y el fin del aislamiento que soportaban ambos países después del Tratado de Versalles.

Con motivo de la muerte de Félix Dzherzhinski en 1926, Mariátegui evocó al presidente de la Cheka, la policía secreta soviética. Iluminaba su retrato con una tonalidad que contrasta con la de los cables informativos de la época. Revisaba su biografía de agitador y las importantes funciones que desempeñó en el Estado de los trabajadores. Con su deceso - sostenía Mariátegui-, la Revolución perdía a uno de «sus más heroicos combatientes», apreciando que no dejó una obra teórica por ser un práctico del marxismo: "Tenía el genio de la organización; no de la creación» (Mariátegui 1989, p. 102).

\section{Trotsky}

Empero, de todos los protagonistas de la Revolución rusa fue León Trotsky a quien el Amauta dedicó el mayor número de escritos 5 . En el primero de estos, publicado en abril de 1924, subrayaba las diversas esferas de su actividad intelectual:

5 La admiración que Mariátegui profesó a Trotsky aparece atestiguada por Luis Alberto Sánchez, quien agrega que, por recomendación suya, leyó ¿A dónde va Inglaterra? y otros libros de la autoría de Trotsky (Sánchez y Oviedo 1975, p. 44). 


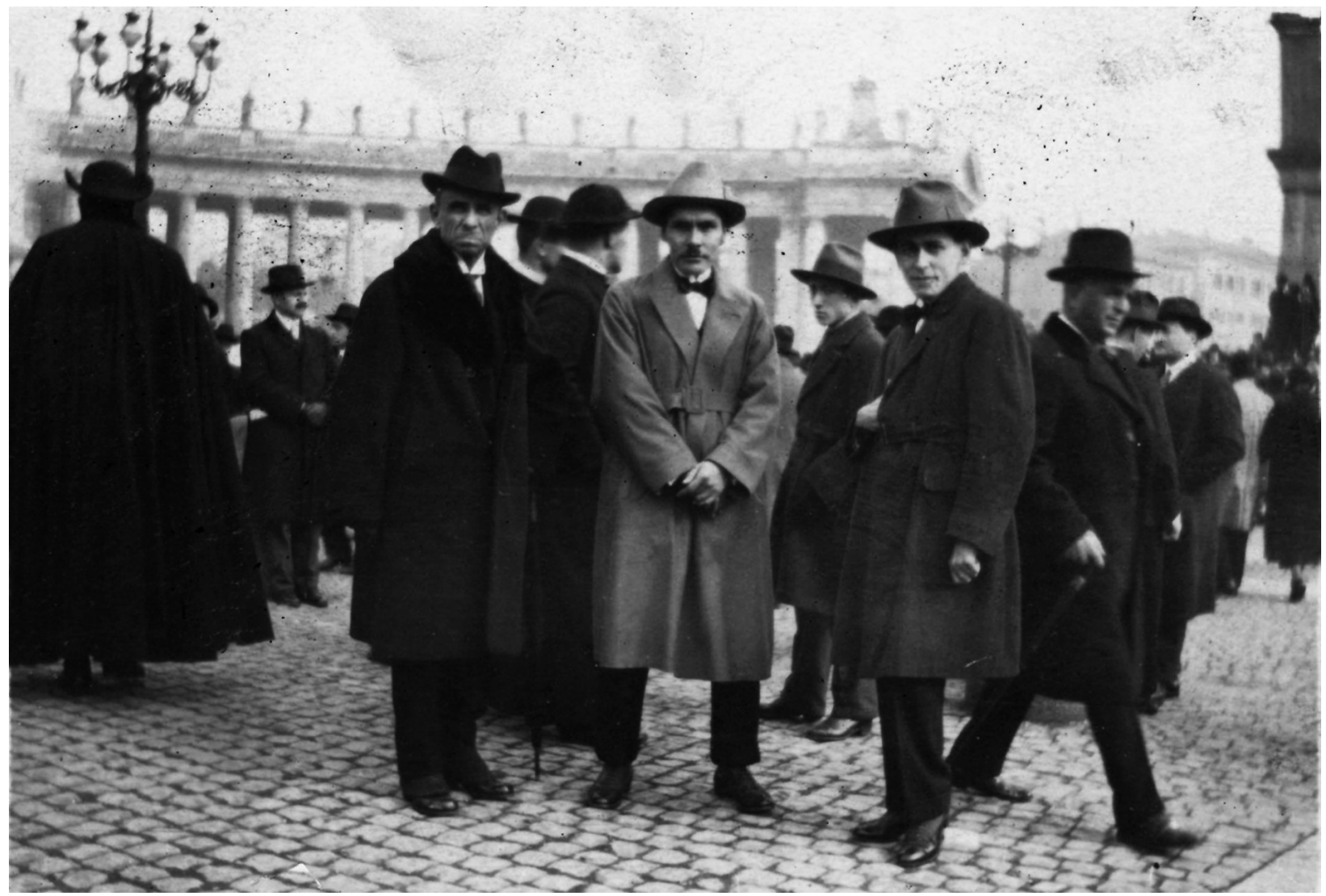

José Carlos Mariátegui en Roma, 1922.

Trotsky no es sólo un protagonista sino también un filósofo, un historiador y un crítico de la Revolución [...] los penetrantes estudios de Lenin no abarcaron sino las cuestiones políticas y económicas. Trotsky, en cambio, se ha interesado además por las consecuencias de la Revolución en la filosofía y en el arte (Mariátegui 1924, p. 981).

Resulta singular esta valoración, más aún cuando la obra de Trotsky en los dominios de la historia y de la crítica literaria empezaba a despuntar en la sociedad soviética; al mismo tiempo, Mariátegui fue uno de los primeros observadores de la actualidad rusa en ocuparse de esta fase de su personalidad. Precisamente, desgrana en contornos claros las ideas de Trotsky sobre el arte y la cultura en la Revolución.

También destaca sus dotes de organizador y realizador al frente del Ejército Rojo, que batió a los enemigos internos y externos de la República soviética. Para Mariátegui, el Ejército Rojo era una creación inédita en la historia militar del mundo, puesto que su existencia tenía por objeto defender la Revolución (Mariátegui 1924, p. 984).
En el artículo "El partido bolchevique y Trotsky», publicado en el mes de enero de 1925, consigna Mariátegui que "Trotsky es uno de los personajes más interesantes de la historia contemporánea» (Mariátegui, 1925, p. 220). Expone el debate que causó su separación del Gobierno de los sóviets, recordando que este dirigente revolucionario era «el más apasionado y ardoroso de todos los que han agitado al bolchevismo desde 1917» (Mariátegui 1925, p. 220). La confrontación en el Partido principió cuando, en octubre de 1923, Trotsky expuso a sus camaradas dos cuestiones urgentes: la necesidad de un "plan de orientación» en la política económica y el establecimiento de un régimen de «democracia obrera» en el Partido. Sus tesis —que encontraron entusiasta apoyo entre la juventud — fueron rechazadas por el Comité Central, y dieron comienzo a una prolongada polémica que ocupó numerosas columnas de Pravda. Ello no obstante, el XIII Congreso del Partido, reunido a principios de 1924, acogió en sus conclusiones la demanda de democratización, añadía Mariátegui. 
Líneas abajo, refiere que la publicación de 1917 , libro de Trotsky acerca de los acontecimientos revolucionarios de aquel año, reavivó la polémica. Admite no conocer esta obra, que aún no se había traducido del ruso ${ }^{6}$, indicando que los últimos documentos polémicos de Trotsky con los que contaba eran los reunidos en El nuevo curso (1923)7. Así, a partir del material consultado, Mariátegui informa que en la obra 1917 se condena la conducta de algunos de los principales líderes de la vieja guardia bolchevique en las jornadas de la insurrección de Octubre (las críticas estaban enfiladas hacia Zinóviev y Kámenev). Sin asomo de duda, Mariátegui infiere que Trotsky quiso demostrar, de este modo, que quienes se equivocaron en un momento tan decisivo para el Partido, carecían de derecho para pretender erigirse en depositarios y herederos únicos del leninismo. Esta publicación acicateó nuevamente la polémica, cuya conclusión fue la condena de los planteamientos de Trotsky (Mariátegui alude aquí al episodio conocido en la historia del Partido Comunista de la Unión Soviética como el «debate literario»). En su opinión, los resultados de la contienda no engendrarían un cisma, habida cuenta de que la vieja guardia había aceptado la necesidad de democratizar el Partido.

$\mathrm{Al}$ recordar episodios de la actuación de Trotsky en el Gobierno, conviene anotar los errores involuntarios en los que incide Mariátegui. Por ejemplo, sostiene que la opinión de Lenin divergió del parecer de Trotsky respecto a los problemas más graves de la revolución; por el contrario, sus puntos de vista convergentes sobrepasaron los desacuerdos, tal como documenta la investigación histórica. También afirma, sin ningún matiz, que Trotsky no quiso aceptar la paz de Brest-Litovsk (en realidad, su postura no se limitaba al asentimiento o rechazo de un acuerdo de paz). Y, además, enuncia que, ante las reivindicaciones de los insurrectos en Kronstadt, Trotsky volvió a discrepar de Lenin; antes bien, estos dirigentes concordaron en que, si los rebeldes no

6 Mariátegui alude al tercer tomo de las obras reunidas de Trotsky, publicadas por Gozisdat, casa editorial del Estado soviético. El prefacio a sus trabajos compilados en ese tomo lleva el título de «1917Lecciones de Octubre», que fue el escrito que incitó la polémica en el Partido.

7 La edición consultada por Mariátegui se publicó en París, en 1924. Además de este libro, tres títulos de Trotsky integraban su biblioteca: Il bolschevismo (Milán, 1920), Nouvelle étape (París, 1922) Terrorismo e Comunismo anti-kautsky (Milán, 1922). (Vanden 1975, p. 141). aceptaban el ultimátum de rendición incondicional propuesto por el Gobierno, se ordenaría el ataque militar a la fortaleza de Kronstadt, tal como aconteció en marzo de 1921.

Es pertinente señalar, asimismo, que si bien Mariátegui indica que la vieja guardia del bolchevismo constituía "casi una burocracia», no incorpora en su análisis la burocratización del aparato del Partido Comunista. Este asunto, denunciado por Trotsky, junto a la campaña por la democracia partidaria y la reorientación del rumbo económico, fueron reivindicaciones centrales de la Oposición de Izquierda en 1923.

Cuatro años después, la expulsión de Trotsky y Zinóviev del Partido Comunista de la URSS, reclamaba para Mariátegui una revisión de la política interna en Rusia; a ello dedicó su artículo «Trotsky y la oposición comunista», publicado en febrero de 1928. Constata que no escasearon en el Partido Bolchevique, aun en vida de Lenin, debates intensos en los que prevalecieron siempre los puntos de vista de su principal líder «por ser los que mejor correspondían a la realidad» (Mariátegui 1928). A su muerte, se produjo el conflicto entre Trotsky y la mayoría bolchevique, abriendo un largo proceso que culminó con la exclusión de la corriente oposicionista. Para explicar esta derrota, estima que, no obstante su destacada actuación como comisario del pueblo y el aprecio de Lenin por su labor, Trotsky no consiguió la confianza total del Partido, cuya organización controlaba la vieja guardia del bolchevismo (Trotsky había ingresado al Partido en 1917 y los bolcheviques de antiguo cuño lo sentían «un poco extrańo y ajeno»). De otra parte, juzga que la Oposición Conjunta en el Partido, en la que Zinóviev y Kámenev se asociaron con Trotsky ${ }^{8}$, se componía de una mezcla de «elementos sospechosos de desviación derechista y social-democrática con elementos incandescentes extremistas» (Mariátegui, 1928). Dicha apreciación debió tener por fuente las informaciones transmitidas desde los órganos oficiales soviéticos y los partidos comunistas afiliados a la Komintern, que al unísono condenaron la plataforma de la Oposición. En otras palabras, Mariátegui acogió la versión oficial acerca del grupo disidente en el Partido.

8 La Oposición Conjunta u Oposición Unificada, nacida en el seno del Partido Comunista de la Unión Soviética en 1926, defendía la orientación internacional de la Revolución rusa. En la política interna, se oponía a la burocratización del Estado y promovía la industrialización y la colectivización de la agricultura. 
ternacional. Esta parcialidad en cuanto a las fuentes consultadas, explicaría algunas de sus críticas sobre planteamientos de carácter político y económico de la Oposición Conjunta en 1927. Por otra parte, es incuestionable que Mariátegui desconoció la plataforma de la fracción opositora, que apenas roza su artículo. La causa de ello es que la dirección del Partido, encabezada por Stalin, prohibió su impresión y divulgación. La plataforma de la Oposición se dio a conocer en el extranjero un año después bajo el título de La situación real de Rusia. En sentido análogo, la «Carta al VI Congreso de la Internacional Comunista» y la "Crítica del programa de la Internacional Comunista», documentos de 1928 en los que Trotsky analiza críticamente los cambios de orientación política de la Komintern se publicaron tras su deportación de la Unión Soviética. De igual manera ocurrió con su testimonio sobre la lucha interna en el Partido (incluida en su autobiografía) y con un sinnúmero de documentos políticos, publicados en 1929 y en los años subsiguientes, después de la muerte de Mariátegui, acaecida en abril de 1930. Estas son las razones por la que el pensador moqueguano no dispuso de los materiales necesarios que le permitieran esbozar un cuadro integral de las formulaciones que se debatieron en el Partido Comunista soviético entre 1926 y 1927.

\section{A manera de conclusión}

Con la instauración del primer Estado de los trabajadores, Mariátegui percibía que la Revolución rusa inauguraba una nueva época en la historia de la humanidad "hacia un régimen de fraternidad, de paz y de justicia» (Mariátegui 1986, p. 53). Considerando su dimensión histórica, Mariátegui juzgaba necesario esclarecer el fenómeno revolucionario, comprender su trascendencia y contribuir a la difusión social de su conocimiento.

Sus escritos sobre la Revolución comprendieron el análisis de temas de índole político, social y cultural; entre estos destacan: las conquistas del régimen socialista, la política exterior de los sóviets, el rol que le cupo a personalidades del bolchevismo en la conducción del Estado y los debates en el seno del Partido Comunista referentes a la edificación y el porvenir del socialismo. En este ámbito de su obra,
Mariátegui se distingue por el eminente dominio de la materia, la sagacidad y agudeza de sus análisis y los acertados juicios que elaboró. Por añadidura, sus artículos entrañan el valor de haber sido pergeñados en la época que acontecieron los hechos que examina y pondera.

En consonancia con lo expuesto, desde la investigación académica se requiere profundizar en los trabajos del Amauta peruano concernientes a Rusia y a diversos sucesos del escenario mundial en los años veinte, que incluyen, verbigracia, las irrupciones revolucionarias en Alemania y China. Mariátegui era consciente de que un estudio cabal de la realidad nacional no podía desvincularse de la comprensión de fenómenos internacionales a la luz del marxismo. Sus perspicaces reflexiones sobre el horizonte mundial, basadas en observaciones directas, en no pocos casos, proyectan un amplio y fecundo territorio para el investigador.

\section{Bibliografía}

Flores Galindo, A. (1982). La agonía de Mariátegui. La polémica con la Komintern (2.a ed.). Lima: Desco.

Mariátegui, J.C. (22 de septiembre de 1923) Lenin. Variedades, 809, 2583-2586.

Mariátegui, J.C. (19 de abril de 1924). Trotsky. Variedades, 842, 981-984.

Mariátegui, J.C. (31 de enero de 1925) El partido bolchevique y Trotsky. Variedades, 883, 220-225.

Mariátegui, J.C. (25 de febrero de 1928) Trotsky y la oposición comunista. Variedades, 1043.

Mariátegui, J.C. (1925). La escena contemporánea. Lima: Editorial Minerva.

Mariátegui, J.C. (1977). Mariátegui: la Revolución de Octubre. Escritos 1917/1930. Selección y estudio de César Lévano. Lima: Siglo XX.

Mariátegui, J.C. (1986). Historia de la crisis mundial. Conferencias (años 1923 y 1924) (11. a ed.). Obras Completas de José Carlos Mariátegui. Lima: Empresa Editora Amauta.

Mariátegui, J.C. (1988). Figuras y aspectos de la vida mundial I (1923-1925) (9. a ed.) Obras Completas de José Carlos Mariátegui. Lima: Empresa Editora Amauta.

Mariátegui, J.C. (1989). Figuras y aspectos de la vida mundial II (1926-1928) (8. a ed.). Obras Completas de José Carlos Mariátegui. Lima: Empresa Editora Amauta. 
Mariátegui, J.C. (1989). Figuras y aspectos de la vida mundial III (1929-1930) (7. a ed.). Obras Completas de José Carlos Mariátegui. Lima: Empresa Editora Amauta.

Mariátegui, J.C. (1991). Cartas de Italia (11. a ed.). Obras Completas de José Carlos Mariátegui. Lima: Empresa Editora Amauta.

NúÑEz, E. (1994). La experiencia europea de Mariátegui (2. a ed.). Lima: Empresa Editora Amauta.

Rouillon, G. (1963). Bio-bibliografía de José Carlos Mariátegui. Lima: Universidad Nacional Mayor de San Marcos.
Rouillon, G. (1975). La creación heroica de José Carlos Mariátegui. Tomo I: La Edad de Piedra (1894-1919). Lima: Editorial Arica.

SÁnchez, L.A. y Oviedo, J.M. (1975). Conversaciones. Lima: Mosca Azul Editores.

Sinclair, Louis (1989). Trotsky: A Bibliography (2a ed.). Vol. 2. Aldershot: Scolar Press.

Sukhanof, N.N. (1970). La Revolución rusa (1917). Barcelona: Luis de Caralt Editor.

VAnden, H.E. (1975). Mariátegui. Influencias en su formación ideológica. Lima: Empresa Editora Amauta. 